\title{
Interstitial lung disease in children: a multicentre survey on diagnostic approach
}

\author{
A. Barbato*, C. Panizzolo*, A. Cracco*, J. de Blic**, R. Dinwiddie***, M. Zach
}

\begin{abstract}
Interstitial lung disease in children: a multicentre survey on diagnostic approach. A. Barbato, C. Panizzolo, A. Cracco, J. de Blic, R. Dinwiddie, M. Zach. (C)ERS Journals Ltd 2000.

ABSTRACT: Chronic interstitial lung disease (ILD) is a rare disorder in the paediatric age group, with a poor prognosis. The diagnostic approach to ILD is based on more or less invasive methods. This study was implemented to verify which methods are the most often used in children.

Questionnaires (333) were sent to members of the European Respiratory Society Paediatric Assembly belonging to 187 European and non-European centres. Questions concerned the use of noninvasive diagnostic methods, e.g. history taking, physical examination, routine laboratory tests, respiratory function tests and radiology (chest radiography, high-resolution computed tomography (HRCT)), and the use of invasive techniques such as bronchoalveolar lavage (BAL), transbronchial biopsy (TBB), open lung biopsy (OLB), video-assisted thoracoscopic biopsy (VAT) and HRCT with fine-needle aspiration biopsy (FNAB).

Thirty eight centres returned the questionnaires and 131 children with ILD were studied. A diagnosis of ILD was achieved in five (3.8\%) patients using noninvasive techniques alone. Using the various biopsy methods, histological assessment was performed on a total of $98(74.8 \%)$ children. The most frequently used invasive technique both alone and in combination was BAL $(83,63.3 \%)$, followed by OLB $(64,48.8 \%)$, TBB $(26,19.8 \%)$ and VAT $(11,8.4 \%)$; FNAB was used in one patient.

In conclusion a diagnosis of interstitial lung disease was reached on the basis of aetiological and/or histological findings in $117(89 \%)$ of the 131 patients studied.
\end{abstract} Eur Respir J 2000; 16: 509-513.

\begin{abstract}
*Dept of Paediatrics, University of Padua, Padua, Italy, **Service de Pneumologie et Allergologie Pédiatriques, Hôpital Enfants Malades, Paris, France, ***Great Ormond Street Hospital for Children, London, UK, Klinik Abteilung für Pneumologie/Allergologie Universität, Klinik für Kinder, Graz, Austria.
\end{abstract}

Correspondence: A. Barbato

Dept of Paediatrics

Via Giustiniani 3

35128 Padova

Italy

Fax: 390498213509

Keywords: Children

diagnostic techniques

interstitial lung disease

lung biopsy

Received: September 151999

Accepted after revision May 222000
Chronic interstitial lung disease (ILD) is a generic term indicating a rare group of chronic pulmonary disorders that cause breathlessness and/or cough, bilateral abnormal opacities on chest radiography or computed tomography (CT), common features of restrictive lung disease, disordered gas exchange, and high morbidity and mortality. The histological findings include derangement of the alveolar wall, loss of alveolar capillary unity and often also involvement of the alveolar air spaces and distal airways [1, 2]. The term "chronic" is used to indicate disease lasting $\geq 1$ month [3].

The prevalence of these disorders in children is not known. Possible causes in immunocompetent patients vary from collagen vascular/connective tissue diseases to granulomatous diseases (e.g. sarcoid, histiocytosis X and hypersensitivity pneumonitis), inherited causes (e.g. familial, neurofibromatosis and metabolic storage disorders), inhalational causes (e.g. environmental gases, fumes, vapours, oil, and inorganic and organic dust), specific entities (bronchiolitis obliterans, bronchiolitis obliterans organizing pneumonia), eosinophilic pneumonia, idiopathic pulmonary haemosiderosis, alveolar proteinosis, lymphatic pulmonary disorders and vascular pulmonary disorders) and idiopathic forms whose aetiology remains unknown [4].

How all these different causes take effect remains to be established. Some authors claim that genetic factors can have a predisposing effect in an apparently normal lung: when the patient is exposed to environmental fibrogenetic stimuli, the alveolar wall cells produce cytokines that trigger an inflammatory process, fibroblastic proliferation, the deposition of new collagen and fibrosis $[2,5,6]$.

The approach to diagnosis includes various steps, including taking a history of the onset of signs and symptoms $[7,8]$, with or without any correlation with environmental causes or other diseases, and physical examination [9], noninvasive techniques, such as pulmonary function tests $[2,7,10-12]$ and radiological examination $[2,13,14]$, and invasive techniques, such as bronchoalveolar lavage (BAL) and biopsy $[15,16]$.

In order to assess which approach is most often used to diagnose ILD in children, the Paediatric Bronchology Group of the European Respiratory Society (ERS) sent out a questionnaire to all members of its Paediatric Assembly.

\section{Materials and methods}

All members of the Paediatric Assembly, belonging to 187 European and non-European centres, listed in the ERS Roster (of July 1995) were sent a total of 333 questionnaires. The questions concerned the different techniques used to diagnose ILD in children, both the noninvasive techniques (e.g. clinical history taking, physical examination, routine laboratory tests, radiological techniques and 
pulmonary function tests) and the invasive techniques (e.g. BAL, transbronchial biopsy (TBB), percutaneous biopsy (fine needle aspiration biopsy - FNAB) with or without high-resolution CT (HRCT), and video-assisted thoracoscopic biopsy (VAT)). There were also questions regarding the possible causes of ILD, such as infectious agents, connective tissue diseases, granulomatous diseases, inherited causes, inhalational causes or idiopathic forms.

The data referred to patients aged $0-18$ yrs and diagnosed between July 1, 1995 and June 30, 1997.

\section{Data presentation}

Replies given as percentages are presented as median, mean and range.

\section{Results}

Of the 187 centres contacted, 38 (20.3\%) completed and returned the questionnaires, which provided data on a total of 155 patients.

The 38 centres involved in the study are listed in the Appendix; 22 of them are university hospitals and 16 general hospitals and all of them are at tertiary level. It is estimated that each centre deals with $\sim 1$ million people, but, being tertiary centres, they draw patients from other areas.

When the answers returned by a given centre were incomplete (this happened in $20 \%$ of cases), the centre was contacted by fax or e-mail and asked to provide any missing information.

From the analysis of the answers regarding the 155 patients, 24 cases were excluded for the following reasons: eight had human immunodeficiency virus-related immunodeficiency; seven had acquired immunodeficiency of unspecified cause; four had received antiblastic therapy; and two had pulmonary tuberculosis; information was lacking on three.

Of the 131 children who were consequently included in the study, 84 (64\%) were male, and 47 (36\%) were female, with a mean age of 6.5 yrs (range $0.75-17.8$ yrs). For 118 children, the questionnaires gave the date of birth and the date of ILD diagnosis, whereas, for 13 , only the date of birth was specified.

The diagnostic methods used are listed in table 1. Using noninvasive techniques alone, such as clinical history tak- ing, physical examination, pulmonary function tests and HRCT, a diagnosis of ILD was only reached in five $(3.8 \%)$ patients. Using noninvasive techniques and BAL, a diagnosis was reached in $28(21.3 \%)$ patients. A diagnosis of ILD was reached in $35(26.7 \%)$ patients using noninvasive techniques and open lung biopsy (OLB); in the majority of cases $(n=27)$, the diagnosis was idiopathic interstitial pneumonia.

Using the various bioptic techniques, histological assessment was performed for a total of $98(74.8 \%)$ children: in 10 cases an infectious agent was isolated, 38 patients had an associated disease (AD), a bioptic diagnosis had not been obtained in four and idiopathic interstitial pneumonia was diagnosed in 46.

A chronic infection was demonstrated in 19 (14.5\%) patients with ILD. Figure 1 shows the age at diagnosis of the 17 children in whom an infectious agent was identified as a potential cause of ILD. The age of greatest incidence of ILD was 3-12 yrs (10 patients.). Adenovirus was the most frequently isolated aetiological agent.

ADs were identified in $51(38.9 \%)$ cases. Figure 2 shows the ADs involved and the age at diagnosis for a total of 48 children. The age of greatest incidence was 612 yrs. The most common ADs were allergic alveolitis and aspiration syndrome, whereas the least common ADs were vascular and lymphatic pulmonary disorders.

In $14(10.6 \%)$ cases, no diagnosis was obtained: there were four nondiagnostic biopsy cases, in which the pathologist could not clearly define a histological pattern, plus 10 cases in which the investigator was unable to identify any specific cause of ILD. In 12 patients the age was reported: 5 of them were between 6-12 yrs.

Idiopathic interstitial pneumonia was diagnosed in 46 (35.1\%) children, including six cases of desquamative interstitial pneumonia (DIP), six of usual interstitial pneumonia (UIP), four of nonspecific interstitial pneumonia (NSIP) and two of lymphoid interstitial pneumonia (LIP). The term nonclassified fibrosis was used to indicate the 28 patients with a clear histological pattern of inflammation and interstitial fibrosis that the pathologist had been unable to classify as DIP, UIP, NSIP or LIP. Figure 3 shows the 41 cases of idiopathic interstitial pneumonia whose age at diagnosis was specified. The age of greatest onset of the various forms of idiopathic interstitial pneumonia was 6 12 yrs (13 patients), but there were also peaks at 2-12 months (eight patients) and 1-3 yrs (eight patients). Two children with a diagnosis of idiopathic interstitial pneumonia were $<2$ months.

Table 1. - Techniques used to diagnose interstitial lung disease in 131 children

\begin{tabular}{|c|c|c|c|c|c|c|c|c|c|c|c|}
\hline & NITS & BAL & TBB & OLB & VAT & $\begin{array}{l}\text { HRCT } \\
\text { and } \\
\text { FNAB }\end{array}$ & $\begin{array}{c}\text { BAL } \\
+ \\
\text { TBB }\end{array}$ & $\begin{array}{c}\text { BAL } \\
+ \\
\text { OLB }\end{array}$ & $\begin{array}{c}\text { BAL } \\
+ \\
\text { TBB } \\
+ \\
\text { OLB }\end{array}$ & $\begin{array}{c}\text { BAL } \\
+ \\
\text { VAT }\end{array}$ & $\begin{array}{c}\text { BAL } \\
+ \\
\text { TBB } \\
+ \\
\text { VAT }\end{array}$ \\
\hline Infection $n$ & 1 & 8 & & 4 & & & 1 & 4 & & 1 & \\
\hline $\mathrm{AD} n$ & 3 & 11 & & 4 & 3 & & 14 & 14 & 1 & 2 & \\
\hline IIP n & & & & 27 & 2 & 1 & 4 & 8 & 1 & 1 & 2 \\
\hline ND n & 1 & 9 & 2 & & & & 1 & 1 & & & \\
\hline Patients $\mathrm{n}$ & 5 & 28 & 2 & 35 & 5 & 1 & 20 & 27 & 2 & 4 & 2 \\
\hline
\end{tabular}

NITS: noninvasive techniques; BAL: bronchoalveolar lavage; TBB: transbronchial biopsy; OLB: open lung biopsy; VAT: videoassisted thoracoscopic biopsy; HRCT: high-resolution computed tomography; FNAB: fine-needle aspiration biopsy; AD: associated disease; IIP: idiopathic interstitial pneumonia; ND: no diagnosis obtained. 


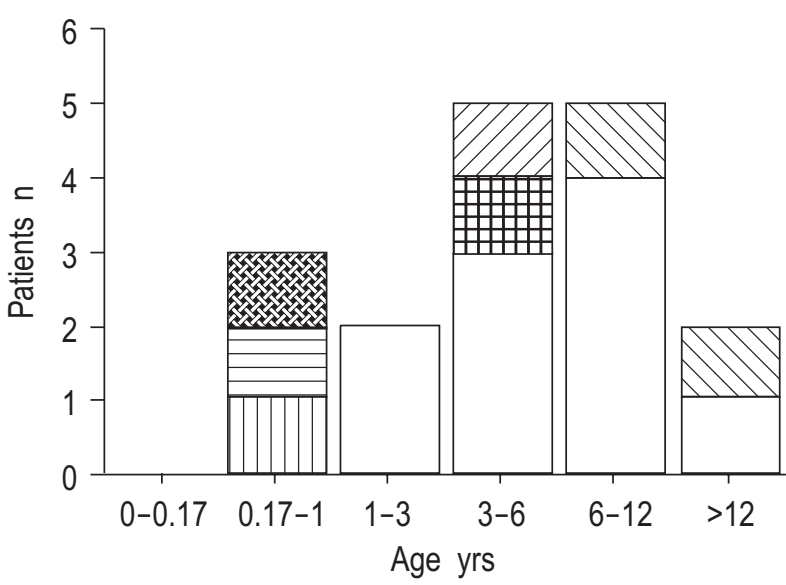

Fig. 1. - Age at diagnosis in 17 children in whom an infectious agent (ש: Chlamydia; $\mathbb{\mathbb { Q }}$ : Mycoplasma; : Pneumocystis; 冒: Epstein-Barr virus; 而: respiratory syncytial virus; 曲: influenza A; $\square$ : adenovirus) was identified as a possible cause of interstitial lung disease.

\section{Discussion}

The purpose of this survey was to assess the diagnostic approach adopted at different paediatric pulmonology centres in relation to a rare and severe pathology such as ILD, which can pose considerable diagnostic and therapeutic problems. Considering the rarity and severity of ILD (which means that patients are often sent to major paediatric pulmonology centres), the number of centres that answered the questionnaire was reasonably high and amounted to $74.5 \%$ of those taking part in a previous survey [17]. However, the number of centres that took part is not sufficient for this study to be considered representative of the situation in Europe.

All the centres that took part in the survey are tertiary level units and so it can be assumed that they are all capable of using the various diagnostic techniques considered here; it is highly unlikely, therefore, that a given diagnostic method was preferred due to the nonavailability of an

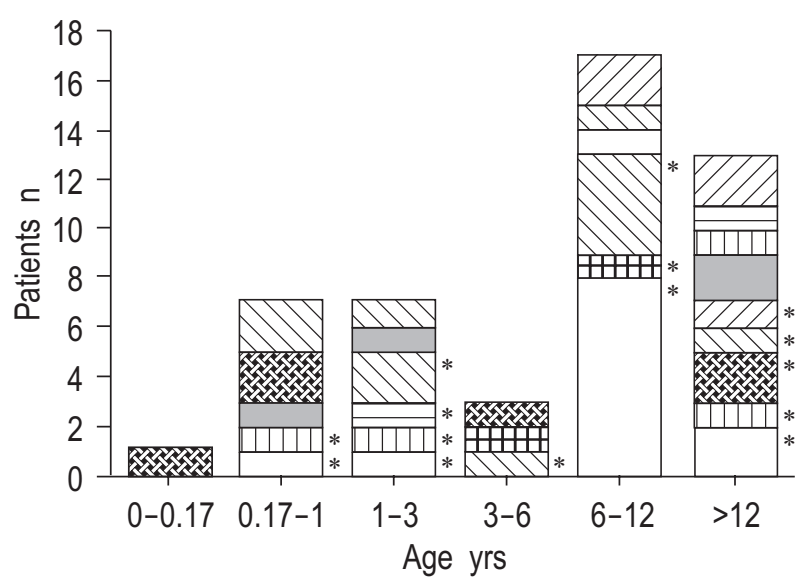

Fig. 2. - Age at diagnosis in 48 children with interstitial lung disease caused by an associated disease ( $\mathbb{Z}$ : sarcoidosis; $\mathbb{\mathbb { Q }}$ : aspiration syndrome; $:$ alveolar proteinosis; 䝿: bronchiolitis obliterans graftversus-host disease; 血: chronic disease; 曲: metabolism disorder; $\square$ : systemic lupus erythematosus; - : histiocytosis; $\mathbb{Z}^{*}$ : granulomatosis; $\mathbb{Q}^{*}$ : haemosiderosis; $\mathbf{x}^{*}$ : vascular pulmonary disorder; 冒*: lymphatic pulmonary disorder; 畘*: bronchiolitis obliterans; 曲*: rheumatoid arthritis; $\square *$ : allergic alveolitis).

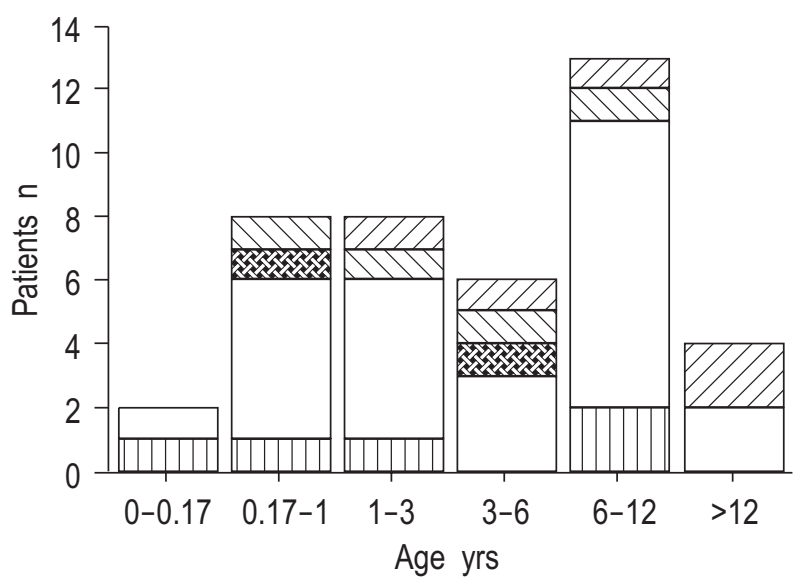

Fig. 3. - Age at diagnosis and histological patterns of idiopathic interstitial pneumonia $(\mathbb{Z}$ : usual interstitial pneumonia; $\mathbb{\mathbb { Q }}$ : nonspecific interstitial pneumonia; : lymphoid interstitial pneumonia; $\square$ : nonclassified fibrosis; $\mathbb{m}$ : desquamative interstitial pneumonia) in 41 children.

alternative, except for the case of VAT, which has only recently been introduced into paediatric practice and was used only 11 times in this survey.

The small number of patients diagnosed using noninvasive techniques alone $(3.8 \%)$ demonstrates that it is generally difficult, without a histological assessment, to arrive at a definite diagnosis of ILD and, consequently, establish a suitable therapy.

As reported elsewhere [15], BAL gave a diagnostic yield of $17 \%$. In the present survey, BAL was the only invasive method used in $28(21.3 \%)$ children, whereas it was used in a supporting role with various other biopsy techniques (OLB, TBB, VAT and percutaneous biopsy during HRCT) in another 55 patients.

The various biopsy techniques (OLB, TBB, VAT and percutaneous biopsy during HRCT) revealed a high proportion of correct diagnoses; a clear-cut diagnosis on aetiological and/or histological grounds was obtained in all but four of the 98 patients who underwent biopsy. This finding is consistent with other reports in the paediatric literature, in which OLB is considered the gold standard for diagnosis and histopathological classification [6, 18], whereas VAT is seen as the technique of the future because it is less invasive and enables a wider view and, consequently, more accurate selection of the area of lung for biopsy, reportedly achieving a diagnostic yield of $60 \%$ [19]. Although it has a diagnostic yield of only $50 \%$ [19], TBB is reported to be particularly useful in monitoring children after lung transplantation [20] or in rare forms of ILD, such as alveolar proteinosis [21]. The tissue samples obtained with TBB are too small, however, and pathologists are critical of this technique.

In the present survey, percutaneous biopsy during HRCT was used in only one case, since the risks related to this diagnostic method are now well known [22, 23].

The known causes of ILD include chronic infections in immunocompetent and immunocompromised children. The present survey ruled out patients with acquired immunodeficiency, tuberculosis or neoplastic disease, but included one case of congenital immunodepression (Bruton's hypogammaglobulinaemia) and four systemic forms, i.e. 
systemic lupus erythematosus [24], rheumatoid arthritis [25], graft-versus-host disease [26] and a case of chronic mucocutaneous candidiasis. The most common chronic infectious agents in this survey were viral [27], particularly adenovirus [28], which was detected in 10 children; however, bacterial infections (Mycoplasma) have also been reported by other authors [2].

Concerning the diseases found in association with ILD, the present survey revealed cases of extrinsic allergic alveolitis [29], aspiration syndrome [30] and, less frequently, vascular pulmonary disorders [31].

Among the idiopathic interstitial pneumonia cases, the pathologist was often unable to use the same classification as for adults [6, 32], confirming that this classification is more difficult to apply to children, although DIP was the form most often described in children up to $1 \mathrm{yr}$ of age $[33,34]$.

In the present survey, UIP was reported in six cases, although the diagnosis of UIP in children is questioned by some authors [6] and confirmed by others [35]. This means, in the authors' opinion, that a difference exists in the interpretation of histological findings by pathologists and, in future studies, it might be feasible to have histological material from a number of centres assessed by the same pathologist.

In conclusion, this survey demonstrates that the gold standard for the diagnosis of interstitial lung disease in children is always lung biopsy, even if the diagnostic approach most often adopted was an association of noninvasive and invasive techniques. This association enabled the diagnosis of interstitial lung disease to be made on the basis of aetiological and/or histological findings in 117 patients, whereas no clear-cut aetiological and/or histological definition of the disease was achieved in only 14 cases.

Centres participating in the survey. Australia: Victoria, Monash Medical Centre; Austria: Graz (Universität Kinderklinik), Vienna (Sozialmedizinisches Zentrum Ost, Kinderinterne Abteilung); Belgium: Louvain (Dept of Paediatric Pulmonology), Yvoir (Cliniques Universitaires de-Mont Godinne); Czech Republic: Prague (Division of Paediatric Pullmonology, 2nd Paediatric Dept, University Hospital, Motol and Paediatric Clinic of the Institute for Postgraduate Medical Studies); Finland: Kuopio (Dept of Paediatrics, University Hospital); France: Le Havre (Centre Hospitalier Du Pneumo-Allergologie Infantile), Paris (Service de Pneumologie et Allergologie Pediatriques, Hospital-Necker-Enfants Malades); Germany: Berlin (Virchow-Klinikum), Bochum (Kinderklinik der Ruhr-Universität), Munich (Kinderpoliklinik), Oldenburg (Klinik für Kinder und Jugendliche); Hungary: Budapest (Paediatric Institute "Svàbhegy" and Semmelweis Medical University), Munkacsy (Pneumological Institute Törökbalint); Italy: Padua (Dept of Paediatrics, University), Perugia (Clinica Pediatrica, University), Trieste (Burlo Children's Hospital); Latvia: Riga (Latvian Medical Academy's Children Hospital); the Netherlands: Groningen (Beatrix Children's Hospital); Norway: Oslo (Children's Clinic National Hospital); Poland: Rabka (National Research Institute for TB and lung disease); Portugal: Porto (Paediatrics Division, Hospital de S. João); Republic of Macedonia: Skopije (Institute for Respiratory Diseases in Children);
Slovenia: Ljubljana (Paediatric Clinic, University Clinical Centre); South Africa: Johannesburg (Children's Hospital); Spain: Gerona (Hospital de Girona), Málaga (Materno-Infantil Hospital), San Sebastián (Hospital Materno-lnfantil N.S. Aranzazu), Valencia (Paediatric Clinic-Hospital Clinic Universitari); UK: London (Respiratory Unit, Great Ormond Street Hospital), Bristol (Children's Hospital); USA: Columbus, Ohio (Children's Hospital), Anchorage, AK (Children's Hospital); Yugoslavia: Belgrade (Mother and Child Institute, and Centre for Paediatric Pulmonology and Tuberculosis).

\section{References}

1. Myers JL. NSIP, UIP, and ABCs of idiopathic interstitial pneumonias. Eur Respir J 1998; 12: 1003-1004.

2. Fan LL, Langston C. Chronic interstitial lung disease in children. Pediatr Pulmonol 1993; 16: 184-196.

3. Fan LL, Kozinetz CA. Factors influencing survival in children with chronic interstitial lung disease. $\mathrm{Am} \mathrm{J}$ Respir Crit Care Med 1997; 156: 939-942.

4. Raghu G. Interstitial lung disease: a diagnostic approach. Am J Respir Crit Care Med 1995; 151: 909-914.

5. Resch B, Eber E, Zach M. Chronische interstitielle Lungenerkrankungen im Kindesalter - ein Überblick. Klin Pädiatr 1997; 209: 59-65.

6. Katzenstein AA, Myers J. Idiopathic pulmonary fibrosis. Clinical relevance of pathologic classification. $A m J$ Respir Crit Care Med 1998; 157: 1301-1315.

7. Fan LL, Mullen ALW, Brugman SM, Inscore SC, Parks DP, White CW. Clinical spectrum of chronic interstitial lung disease in children. $J$ Pediatr 1992; 121: 867-872.

8. Osika E, Muller M-H, Boccon-Gibod L, et al. Idiopathic pulmonary fibrosis in infants. Pediatr Pulmonol 1997; 23: 49-54.

9. Fan LL, Kozinetz CA, Deterding RR, Brugman SMB. Evaluation of a diagnostic approach to pediatric interstitial lung disease. Pediatrics 1998; 101: 82-85.

10. Steinkamp G, Müller K-M, Schirg E, von Der Hardt H. Fibrosing alveolitis in childhood. Acta Paediatr Scand 1990; 79: 823-831.

11. Erbes R, Schaberg T, Loddenkemper R. Lung function tests in patients with idiopathic pulmonary fibrosis. Chest 1997; 111: 51-57.

12. Raghu G, Johnson WC, Lockhart D, Mageto Y. Treatment of idiopathic pulmonary fibrosis with a new antifibrotic agent, pirfenidone. Am J Respir Crit Care Med 1999; 159: 1061-1069.

13. Lee JS, Gong G, Song KS, Kim SD, Lim TH. Usual interstitial pneumonia: relationship between disease activity and the progression of honeycombing at thin-section computed tomography. $J$ Thorac Imag 1998; 13: 199 203.

14. Hartman TE, Primack SL, Kang E-U, et al. Disease progression in usual interstitial pneumonia compared with desquamative interstitial pneumonia. Chest 1996; 110: 378-382.

15. Fan LL, Lung MCL, Wagener JS. The diagnostic value of bronchoalveolar lavage in immunocompetent children with chronic diffuse pulmonary infiltrates. Pediatr Pulmonol 1997; 23: 8-13.

16. Coren ME, Nicholson AG, Goldstraw P, Rosenthal M, Bush A. Open lung biopsy for diffuse interstital lung disease in children. Eur Respir J 1999; 14: 817-821.

17. Barbato A, Magarotto $M$, Crivellaro $M$, et al. Use of paediatric bronchoscope, flexible and rigid, in 51 European centres. Eur Respir J 1997; 10: 1761-1766. 
18. Kramer MR, Berkman N, Mintz B, Godfrey S, Saute M, Amir G. The role of open lung biopsy in the management and outcome of patients with diffuse lung disease. Ann Thorac Surg 1998; 65: 198-202.

19. Fan LL, Kozinetz CA, Wojetezak HA, Chatfield BA, Cohen AH, Rothenberg SS. Diagnostic value of transbronchial, thoracoscopic and open lung biopsy in immunocompetent children with chronic interstitial lung disease. J Pediatr 1997; 131: 565-569.

20. Whitehead B, Scott JP, Helms P, et al. Technique and use of transbronchial biopsy in children and adolescents. Pediatric Pulmonol 1992; 12: 240-246.

21. Wallis C, Whitehead B, Malone M, Dinwiddie R. Pulmonary alveolar microlithiasis in childhood: diagnosis by transbronchial biopsy. Pediatr Pulmonol 1996; 21: 6264.

22. Smyth R, Carty H, Thomas H, Van Velzen D, Heaf D. Diagnosis of interstitial lung disease by a percutaneus lung biopsy sample. Arch Dis Child 1994; 70: 143-144.

23. Spencer DA, Alton HM, Raafat F, Weller PH. Combined percutaneous lung biopsy and high-resolution computed tomography in the diagnosis and management of lung disease in children. Pediatr Pulmonol 1996; 22: 111-116.

24. Min JK, Hong YS, Park SH, et al. Bronchiolitis obliterans organizing pneumonia as an initial manifestation in patients with systemic lupus erythematosus. $J$ Rheumatol 1997; 24: 2254-2257.

25. Gabbay E, Tarala R, Will R, et al. Interstitial lung disease in recent onset rheumatoid arthritis. Am J Respir Crit Care Med 1997; 156: 528-535.

26. Palmas A, Tefferi A, Myers JL, et al. Late-onset non- infectious pulmonary complications after allogenic bone marrow transplantation. Br J Haematol 1998; 100: 680687.

27. Yonemaru M, Kasuga I, Kusumoto H, et al. Elevation of antibodies to cytomegalovirus and other herpes viruses in pulmonary fibrosis. Eur Respir J 1997; 10: 2040-2045.

28. Egan JJ, Woodcock AA, Stewart JP. Viruses and idiopathic pulmonary fibrosis. Eur Respir J 1997; 10: 14331437.

29. Salvaggio JE. Extrinsic allergic alveolitis (hypersensitivity pneumonitis): past, present and future. Clin Exp Allergy 1997; 27 (Suppl. 1): 18-25.

30. Midulla F, Strappini PM, Ascoli V, et al. Bronchoalveolar lavage cell analysis in a child with chronic lipid pneumonia. Eur Respir J 1998; 11: 239-242.

31. Sondheimer HM, Lung MC, Brugman SM, Ikle DN, Fan LL, White CW. Pulmonary vascular disorders masquerading as interstitial lung disease. Pediatr Pulmonol 1995; 20: 284-288.

32. American Thoracic Society. Idiopathic pulmonary fibrosis: diagnosis and treatment. International consensus statement. Am J Respir Crit Care Med 2000; 161: 646664.

33. Bush A, du Bois R. Congenital and pediatric interstitial disease. Curr Opin Pulm Med 1996; 2: 347-356.

34. Balasubramanyan N, Murphy A, O'Sullivan J, O'Connell EJ. Familial interstitial lung disease in children: response to chloroquine treatment in one sibling with desquamative interstitial pneumonitis. Pediatr Pulmonol 1997; 23: 5561.

35. Bokulic RE, Hilman BC. Interstitial lung disease in children. Pediatr Clin North Am 1994; 41: 543-567. 